\title{
Childhood adversities and prior involvement with child protective services
}

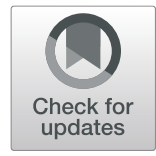

Shakira F. Suglia ${ }^{1,2^{*}}$, Erin R. Kulick ${ }^{3}$ and Jocelyn Brown ${ }^{4}$

\begin{abstract}
Objectives: We aimed to determine the relation between childhood adversities and prior involvement with Child Protective Services (CPS) history among children presenting for evaluation at a Child Advocacy Center.

Study design: The study evaluated children presenting to a Child Advocacy Center (CAC) from 2009 to 2014. A five-item child adversity measure, based on mother's report, was characterized into a scale of none, one, or two or more adversities. Caseworkers at the CAC assessed whether families had a prior history of involvement with CPS.

Results: Among the 727 children included in the analyses, 43\% had a prior history of involvement with CPS. Twenty-six percent of the children experienced one childhood adversity while $29 \%$ experienced two or more. In regression analyses adjusting for socio-demographics, experiencing one (Prevalence Ratio (PR) 1.25 95\%Cl 1.0-1.5) or two or more adversities (PR1.67 95\%Cl 1.4, 2.0) was associated with higher prevalence of CPS history compared to those who reported none.

Conclusions: Childhood adversities are associated with prior contact with CPS, suggesting there are missed opportunities to provide services to high-risk families. CACs may be in a unique position to advocate for families and prevent further victimization of children.
\end{abstract}

Keywords: Child maltreatment, Re-victimization, Child protective services, Adverse child experiences, Social stressors

\section{Introduction}

Childhood maltreatment is a toxic stressor prevalent in the United States (US) (Shonkoff and Garner 2012) that often co-occurs with other adversities, including parental substance use, parental psychopathology, divorce, and other forms of violence exposure (Connell et al. 2007). However, these adverse experiences, commonly known as adverse child experiences or ACEs, are not consistently assessed in clinical settings, including emergency room departments or child advocacy centers (CAC) were children who are victims of maltreatment might be presenting (Campbell et al. 2019; Bethell et al. 2016). During child abuse investigations the focus is generally on the evaluation of maltreatment and often other adversities that families may be facing are not addressed (Campbell et al. 2019). Families who are facing multiple

\footnotetext{
* Correspondence: Shakira.suglia@emory.edu

${ }^{1}$ Department of Epidemiology, Rollins School of Public Health, Emory

University, 1518 Clifton Rd, Atlanta, GA 30322, USA

${ }^{2}$ Department of Epidemiology, Mailman School of Public Health, Columbia

University, New York, NY, USA

Full list of author information is available at the end of the article
}

adversities are the most vulnerable, often having low economic, social and emotional resources and thus children may be most at risk for repeat victimization (Connell et al. 2007), identifying and addressing these factors when children are first involved with clinical settings, particularly for suspicion of abuse, may prevent repeat victimization and facilitate prompt referrals to trauma-informed mental health care.

We examined the prevalence of adversities among children seen at a CAC for suspicion of child abuse and their relation to prior involvement with Child Protective Services (CPS).

\section{Methods}

We extracted medical record data from children seen at the Manhattan Child Advocacy Center (MCAC) from February 2009 to November 2014 for suspicion of exposure to sexual and/or physical abuse. The MCAC brings together professionals and agencies as a multidisciplinary team to investigate physical and sexual abuse cases and coordinate services to children and their 
families (Cross et al. 2007). Specifically, representatives from CPS, law enforcement, district attorney's office, Safe Horizon (a national victim assistance organization) and a medical team are involved. Children and their caretakers are referred for further investigation and medical assessment after a child abuse report is made to law enforcement and/or CPS. Certain criteria for evaluation by the multidisciplinary team at the MCAC must be met: familial or non-familial sexual offenses of children 12 years and under, physical abuse of children 10 years and under, the family resides in New York County and /or the alleged criminal activity occurred in New York County. Children are first interviewed forensically by Safe Horizon trained professionals. The purpose of every forensic interview conducted at the MCAC is to obtain a statement from a child, in a developmentally, age appropriate and culturally sensitive, unbiased and fact-finding manner that will support informed and fair decision making by the Manhattan multidisciplinary team. A medical examination by a board certified child abuse pediatrician is also conducted in about half of the children interviewed. Lastly, the caretaker, usually the non-offending parent is also interviewed by the child abuse pediatrician. Mandated reporting laws suggest that a report is made based on suspicion of abuse, not on definitive proof of abuse. It is then possible that there was no evidence of abuse or neglect after an investigation and therefore that there may not be any abuse.

Table 1 Child and Maternal Characteristics by Prior Child Protective Services (CPS) History $(n=727)$

\begin{tabular}{|c|c|c|c|c|c|c|}
\hline & \multicolumn{2}{|c|}{ Prior CPS History $(n=312)$} & \multicolumn{2}{|c|}{ No Prior CPS History $(n=415)$} & \multicolumn{2}{|c|}{ Total $(n=727)$} \\
\hline & Mean (SD) & Range & Mean (SD) & Range & Mean (SD) & Range \\
\hline Child's Age & $8.1(4.0)$ & $0.2-17.8$ & $7.7(4.0)$ & $0.5-17.3$ & $7.9(4.0)$ & $0.2-17.8$ \\
\hline \multirow[t]{2}{*}{ Mother's Age } & $34.2(8.6)$ & $14.0-63.0$ & $33.8(7.7)$ & $14.0-63.0$ & $34.0(8.1)$ & $14.0-64.3$ \\
\hline & $n$ & $\%$ & $\mathrm{n}$ & $\%$ & $n$ & $\%$ \\
\hline \multicolumn{7}{|l|}{ Child's Gender } \\
\hline Male & 107 & 43.5 & 139 & 56.5 & 246 & 33.8 \\
\hline Female & 205 & 42.6 & 276 & 57.4 & 481 & 66.2 \\
\hline \multicolumn{7}{|l|}{ Race/Ethnicity* } \\
\hline White & 12 & 21.1 & 45 & 79.0 & 57 & 7.8 \\
\hline Black & 122 & 56.7 & 93 & 43.3 & 215 & 29.6 \\
\hline Hispanic & 149 & 38.9 & 234 & 61.1 & 383 & 52.7 \\
\hline Other & 29 & 40.3 & 43 & 59.7 & 72 & 9.9 \\
\hline \multicolumn{7}{|l|}{ Mother's Primary Language* } \\
\hline English & 241 & 49.5 & 246 & 50.5 & 487 & 67.0 \\
\hline Spanish & 45 & 28.9 & 111 & 71.2 & 156 & 21.5 \\
\hline Other & 26 & 31.0 & 58 & 69.0 & 84 & 11.6 \\
\hline \multicolumn{7}{|l|}{ Mother's Education Level* } \\
\hline$<\mathrm{HS}$ Grad & 54 & 41.9 & 75 & 58.1 & 129 & 17.7 \\
\hline HS Graduate & 138 & 48.9 & 144 & 51.1 & 282 & 38.8 \\
\hline Some College/ College Grad & 120 & 38.0 & 196 & 62.0 & 316 & 43.5 \\
\hline Public Assistance* & 170 & 50.3 & 168 & 49.7 & 338 & 46.5 \\
\hline \multicolumn{7}{|l|}{ Individual adverse items } \\
\hline Domestic Abuse* & 168 & 51.9 & 156 & 48.2 & 324 & 44.6 \\
\hline Problems with Police* & 78 & 61.9 & 48 & 38.1 & 126 & 17.3 \\
\hline Drug/Alcohol Problem* & 34 & 77.3 & 10 & 22.7 & 44 & 6.1 \\
\hline Mental health Problems* & 114 & 59.1 & 79 & 40.9 & 193 & 26.6 \\
\hline Ongoing Custody Battle* & 50 & 61.0 & 32 & 39.0 & 82 & 11.3 \\
\hline \multicolumn{7}{|l|}{ Adversity Category* } \\
\hline None & 73 & 27.2 & 203 & 72.8 & 279 & 38.4 \\
\hline One & 96 & 41.9 & 133 & 58.1 & 229 & 31.5 \\
\hline Two or more & 140 & 63.9 & 79 & 36.1 & 219 & 30.1 \\
\hline
\end{tabular}

${ }^{*} p<0.05$ comparing covariates and prior CPS history 
Of 1069 children who presented at MCAC between 2009 and 2014 and were referred for medical evaluation, 727 were interviewed forensically by Safe Horizon trained professionals and the caretaker, usually the nonoffending parent, was also interviewed by the child abuse pediatrician. During the medical assessment, the mother was interviewed alone and asked about past history of mental illness, her own history of incarceration or arrest, drug or alcohol use and history of intimate partner violence (IPV). To assess IPV, mothers were asked whether someone in the past year kicked, hit or punched them and whether in a past relationship they felt afraid or were harmed by their partner (Basile et al. 2007). Presence of an ongoing custody battle was also assessed to define parental discord. Caseworkers obtained access to prior CPS reports. The study was approved by the Institutional Review Board at Columbia University.

\section{Data analyses}

Bivariate analyses were conducted to assess the relationship between child and maternal characteristics and adversities with prior CPS history. Given the high prevalence of CPS involvement, binomial regression analyses were conducted to estimate the association between adversities and CPS involvement. Unadjusted analyses were first conducted followed by a regression model adjusting for child characteristics (race/ethnicity, gender, age, and type of abuse), mother characteristics (age, primary language and education), and receipt of public assistance. All analyses were conducted in SAS 9.3.

\section{Results}

The adversities' prevalence was high; $32 \%$ of mothers reported one adversity and $30 \%$ reported two or more. A higher prevalence of adversities was associated with prior CPS report (Table 1).

In binomial regression analyses, the greater the number of adversities, the more likely a history of prior CPS report (experiencing one adversity [Prevalence Ratio (PR) $1.2595 \%$ CI $1.04,1.50$ or 2 or more adversities PR $1.6795 \%$ CI 1.41, 1.98], even after adjusting for sociodemographic factors. (Table 2).

\section{Discussion}

It has been suggested that pediatricians could support CPS- involved families with close follow-up and referrals to appropriate services in the community (Campbell et al. 2012). Child abuse pediatricians can do just that within their CACs' role: assessing adverse conditions for each family seen, connecting families to community based services in collaboration with the multidisciplinary team, and when possible involve the child's pediatrician in the overall treatment plan of the family. Coordinated and integrated collaboration between primary care
Table 2 Binomial Regression Models of the Childhood Adversities and prior Child Protective Service (CPS) History ( $N=$ 727)

\begin{tabular}{lll}
\hline & $\begin{array}{l}\text { Unadjusted Model } \\
\text { PR }[95 \% \mathrm{Cl}]\end{array}$ & $\begin{array}{l}\text { Adjusted Model } \\
\text { PR }[95 \% \mathrm{Cl}]\end{array}$ \\
\hline Adversity Category & & \\
None & Ref & Ref \\
One & $1.57(1.20-2.00]^{\mathrm{a}}$ & $1.25[1.04-1.50]^{\mathrm{a}}$ \\
Two or more & $2.36[1.89-2.91]^{\mathrm{a}}$ & $1.67[1.41-1.98]^{\mathrm{a}}$ \\
\hline
\end{tabular}

${ }^{a} p$-value $<0.05$

${ }^{a}$ Model Adjusted for child gender, race/ethnicity, age, type of abuse, maternal age, primary language spoken at home, education level, and receipt of public assistance

providers and investigative teams will ensure the delivery of needed services at the community level for families for whom adversities are known (Campbell et al. 2019; Bair-Merritt and Zuckerman 2016).

We acknowledge adversities were self-reported by the mother in the setting of a child abuse investigation and some were not assessed with validated scales. While the CAC population does not reflect the entire CPS population, our study findings provide further evidence that maltreated children are exposed to a host of other family dysfunction factors, addressing adversities at the first encounter of suspicion for child abuse may prevent further victimization of children. In addition, our study further supports the need to support a family in the face of an investigation by assessing and addressing other adversities; encouraging collection of data with more accurate measures of adversities, by using for example, documented domestic violence reports or prior child abuse reports and presenting an opportunity to study new models that integrate multiple social factors to build safe, stable and nurturing relations for children (Sege et al. 2017).

Acknowledgements

Not applicable.

\section{Authors' contributions}

SFS conceptualized the study, supervised data analyses and wrote initial draft of the manuscript. EK conducted statistical analyses, contributed to the initial manuscript draft. JB conceptualized study and contributed to initial manuscript draft. All authors read and approved the final manuscript.

\section{Funding}

This work was supported by the Center for Injury Science and Prevention at Columbia University.

Availability of data and materials

Please contact author for data requests.

Ethics approval and consent to participate

The study was approved by the Institutional Review Board at Columbia University.

Consent for publication

Not applicable. 


\section{Competing interests}

The authors declare that they have no competing interests.

\section{Author details}

'Department of Epidemiology, Rollins School of Public Health, Emory University, 1518 Clifton Rd, Atlanta, GA 30322, USA. ²Department of Epidemiology, Mailman School of Public Health, Columbia University, New York, NY, USA. ${ }^{3}$ Department of Epidemiology, Brown University, Providence, RI, USA. ${ }^{4}$ Department of Pediatrics, Columbia University Medical Center, New York, NY, USA

Received: 3 September 2019 Accepted: 15 November 2019

Published online: 09 December 2019

\section{References}

Bair-Merritt MH, Zuckerman B. Exploring Parents' adversities in pediatric primary care. JAMA Pediatr. 2016;170((4)):313-4.

Basile K, Hertz M, Back S. Intimate partner violence and victimization assessment instruments for use in healthcare settings: version 1. Centers for Disease Control and Prevention, Naional Center for Injury Prevention and Control: Atlanta, GA; 2007.

Bethell C, Gombojav N, Solloway M, Wissow L. Adverse childhood experiences, resilience and mindfulness-based approaches: common denominator issues for children with emotional, mental, or behavioral problems. Child Adolesc Psychiatr Clin N Am. 2016;25((2)):139-56.

Campbell KA, Thomas AM, Cook LJ, Keenan HT. Longitudinal experiences of children remaining at home after a first-time investigation for suspected maltreatment. J Pediatr. 2012;161((2)):340-7.

Campbell KA, Wuthrich A, Norlin C. We have all been working in our own little silos forever: exploring a Cross-sector response to child maltreatment. Acad Pediatr. 2019.

Connell CM, Bergeron N, Katz KH, Saunders L, Tebes JK. Re-referral to child protective services: the influence of child, family, and case characteristics on risk status. Child Abuse Negl. 2007;31((5)):573-88.

Cross TP, Jones LM, Walsh WA, Simone M, Kolko D. Child forensic interviewing in Children's advocacy centers: empirical data on a practice model. Child Abuse Negl. 2007:31((10)):1031-52

Sege R, Bethell C, Linkenbach J, Jones J, Klika B, Pecora P. Balancing adverse childhood experiences with HOPE: new insights into the role of positive experience on child and family development. Boston: The Medical Foundation; 2017

Shonkoff JP, Garner AS. The lifelong effects of early childhood adversity and toxic stress. Pediatrics. 2012;129(1):e232-46.

\section{Publisher's Note}

Springer Nature remains neutral with regard to jurisdictional claims in published maps and institutional affiliations.

Ready to submit your research? Choose BMC and benefit from:

- fast, convenient online submission

- thorough peer review by experienced researchers in your field

- rapid publication on acceptance

- support for research data, including large and complex data types

- gold Open Access which fosters wider collaboration and increased citations

- maximum visibility for your research: over $100 \mathrm{M}$ website views per year

At $\mathrm{BMC}$, research is always in progress.

Learn more biomedcentral.com/submissions 